\title{
Challenges vs. opportunities: Competitive intelligence and global strategies
}

Received (in revised form): 8th May, 2000

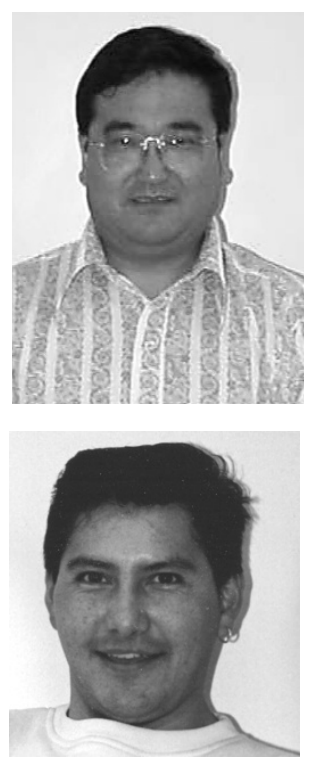

\section{Robert G. Tian}

is an associate professor at Erskine College, South Carolina. With three Master's degrees, an MBA and a PhD, Robert enjoys looking at business from a cross-cultural perspective. Competitive intelligence on a global basis is an area he is currently researching.

\section{Byron G. Tobar}

Byron is an international trade consultant based in Toronto. After finishing his MBA at Wilfrid Laurier University, he developed and established the International Trade Program at Communitech, a technology association. In this role he provided local business people with services such as export awareness, education, training, development and implementation of export plans, export-readiness assessments and facilitated access to government resources.

Abstract In today's highly competitive global marketplace, a company that owns knowledge and information is no longer enough to compete adequately. It is imperative firms implement competitive intelligence $(\mathrm{Cl})$ programmes to meet present and future challenges. This needs to occur or firms run the risk of losing their share of the market. Global $\mathrm{Cl}$ is instrumental in enabling firms to successfully launch products, compete effectively or enter a new market in a timely and specific manner, it assists in facilitating effective decisions. This paper highlights the challenges and opportunities of global competitive intelligence.

\section{INTRODUCTION}

Economic globalisation and the development of the Internet have created great opportunities for competitive intelligence $(\mathrm{CI})$ professionals, how to grasp the opportunity is totally up to individual firms and their CI professionals. A good sense of history, politics and cultural and business knowledge is a prime requirement in building a global CI programme. These are the tools a CI analyst must possess to understand cultural realities and trends. By doing so the CI practitioner can fully understand the effect religion, ethnic backgrounds and histories bring to a culture. With this knowledge, the analyst is then able to piece together the puzzle of global competitive intelligence. In today's highly competitive global village, knowledge and information has to be analysed and converted to intelligence to be effective and worthwhile. Only in this way can the firm be assured of success in the global market.

The term competitive intelligence was originally used by the military in terms of obtaining the secrets and information of opposing forces for strategic planning. In the business world competitive intelligence is used to identify realistic threats and opportunities, to avoid surprises and to improve a firm's competitive position within a particular market. More specifically, it is defined as any information obtained from sources 
external to the firm, which can help improve the firm's performance. It is a special strategy that helps a firm anticipate and ultimately survive the rigours of increasingly competitive markets, it is the process of converting raw information by analysis into intelligence.

It is expected that international labour distribution and various international marketplaces make it possible for firms to seek profitable opportunities internationally. There is a pervasive belief that having a presence, or an infrastructure, around the world will assure business competitiveness and, therefore, success. ${ }^{1}$ How to assess foreign industry, international competitors, suppliers, foreign marketplaces and the intricacies of doing business abroad are sometimes overlooked, however. This is the role global CI satisfies.

In spite of the growing number of international businesses, there is little knowledge of how firms gather information in the global arena. This lack of information not only affects firms in terms of international competitiveness, but also has a negative impact on the efficient use of global resources. It is necessary, therefore, for the business world to study international competitive intelligence and to find a solution for the effective conduct and implementation of global competitive intelligence. This paper highlights the challenges and opportunities of global competitive intelligence. The first section details the challenges; the second indicates current organisational practices; and the third presents opportunities and the way challenges are overcome. The report concludes with a description of how an international CI programme can be developed. It is very important for the business world to realise that conducting an international competitive intelligence programme is very different to a domestic one.

\section{CHALLENGES: CROSS-CULTURAL FACTORS IN INTERNATIONAL COMPETITIVE INTELLIGENCE}

Before discussing the challenges it is useful to begin with several basic issues concerning CI at a strategic level. Competitive intelligence as a business strategy for any firm should start, according to CI scholars, ${ }^{2,3}$ by the CI professional answering the following questions:

- what are the characteristics of my industry

- who are the players

- what are the current positions of my competitors

- what moves are my competitors likely to make

- what are the probabilities attached to each strategic alternative

- what companies might have the potential to enter the market

- what moves can I make to achieve a competitive advantage?

These questions cover most of the fundamental issues in the CI field.

Competitive intelligence professionals usually rely on publicly accessible, open-source information. These sources include academic publications, trade shows, magazines, news reports, trade journals, speeches, websites and the Internet. Governmental reviews, benchmarking reports, the Securities Exchange Commission, career advertisements, lawsuits and bankruptcy filings, and patent registrations also provide vital information. Competitive intelligence professionals use all their resources to collect information. They then analyse the information collected in order to provide recommendations and solutions to decision-makers.

The core factor in the CI process is the information flow: how to get the information, process it and how to make 
use of it. In international CI, obtaining information from foreign markets is essential for developing successful market entry or defensive strategies. The process is the same as that in the home market but the analysis has to consider the characteristics and nuances of the foreign environments, such as cultural issues. ${ }^{4}$ Normally, companies fail in their entry into foreign markets because of serious errors and misjudgments concerning the social, cultural and political environment. Obviously, conducting CI on a global basis is much more complicated than on a domestic one. ${ }^{5}$ Prescott and Gibbons identified five reasons for this:

- countries vary in the types, timeliness, accuracy and motives for data collection

- the attitudes concerning individuals attempting to collect data and the ethical standards for acquiring information vary from country to country

- the technologies for the production, storage, movement, analysis and timing of information vary dramatically across countries

- language barriers are important for both the collection and analysis of information

- country-specific idiosyncrasies need to be addressed. ${ }^{6}$

In an attempt to address country-specific qualities the CI analyst needs to consider culture. Cultural factors have a major influence on the result of the analysis. Simpkins has identified eight cultural variables to be considered:

- action: is the culture relationshipcentred where stress is placed on working for the experience rather than the accomplishment? Or is it more task-oriented where stress is placed on actions that achieve the goal? This would be the societal view of achievement and work as goals

- competitiveness: is more emphasis placed on competition for rewards, or cooperation for the benefit of life and relationships

- communications: are communications high context, meaning that shared experiences make certain things understood without the need to express them verbally, or low context, where explicit knowledge and facts must be expressed. Are communications direct or indirect? Is the preference for explicit one-to-one communications, or more of an implicit dialogue and avoidance of conflict? Are communications formal, where emphasis is placed on protocol and social customs, or informal, where restrictions are dispensed with

- environment: do people feel they can dominate the environment to fit their needs, should they live in harmony with it, or do they feel that their world is controlled by fate and chance

- individualism: is the individual more important than the group, or are the needs of the individual subordinated to the group interests? Is loyalty to self or society

- structure: a society may either lean towards order, with its predictability and rules, or flexibility, where tolerance of unpredictable situations and ambiguity are acceptable

- thinking: does the culture favour inductive reasoning based on experience and experimentation, or deductive reasoning based on theory and logic

- time: is there a concentration on one task at a time, with a commitment to schedules, or an emphasis on multiple tasks, with relationships being the most important? Is punctuality precise and fixed, or is it fluid and loose? ${ }^{7}$ 
In addition to the above, Sheinin provides the following variables:

- power and authority: the dominant views of authority versus subordinates. The power distance between individuals

- union and management: the extent of union-management cooperation to achieve a successful company

- social values: the dominant view of wealth and material gain — attitudes towards and the desire for material wealth versus religious satisfaction, the good life or other non-material stimuli found more in traditional societies

- risk view: the view of risk taking as a measured calculation of anticipated success

- change and innovation: the view of change or innovation - do people in a society embrace and adapt to change which promises to improve productivity or do they maintain their basic faith in traditions or old ways of doing things

- ethical values: the view of ethical standards and moralities

- gender: the degree of masculinity $v s$. femininity. ${ }^{8}$

The objective of the CI practitioner in a global setting is to research and gather high quality, accurate and relevant information to complete an analysis. If the analyst does not consider the above variables, serious errors of judgment can be made. The CI investigator may inadvertently impose their cultural bias or make culturally-based assumptions, or be oblivious to the perceptions of the host nationals to the individual CI professional cultural conditioning. After all, analyses flawed by a lack of cultural awareness will affect strategic entry decisions.

\section{LESSONS AND EXPERIENCE: A CRITICAL REVIEW OF CURRENT PRACTICES}

Competitive intelligence as one of a dynamic business's functions is relatively new to managers, let alone the international CI programme. Calof reports that many managers are careless in their international collection efforts; not enough emphasis is given to global CI even when firms are entering a new foreign market. He further maintains that there is an abundance of studies on how to gather information in the home country but it is not known whether these findings apply in an international context. Calof found that even when it was something as important as the decision to open up a foreign branch, few executives did anything more than discuss it with a few friends. Only 35 per cent of companies conducted a formal study, 18 per cent considered alternatives for international entries. ${ }^{9}$ The reasons could be many, but the crucial point is that the executives are not well exposed to the international environment.

Business competition in the end is the competition in the marketplace. The traditional international or multinational approach to business concentrates largely on geographic markets, developing a distinct marketing mix for each market. Traditional approaches negate experience curve effects that can be gained by using the same marketing mix in more than one market. Global business, in contrast, concentrates on product, emphasising their similarities regardless of the geographic areas in which they are located. It does not, however, ignore differences; these differences are taken into account when implementing the marketing programme. For instance, advertising is translated into different languages for different national markets. And different distribution strategies are 
developed for areas with different distribution structures. ${ }^{10}$

All these business decisions should be based on a good understanding of differences across national boundaries as well as cross-culturally. By the same token all these differences need to be seriously considered before conducting international CI programmes. Many current international CI practitioners neglect this crucial point. For instance, Griffith notes that many US marketers are hard pressed to understand the French government's actions in restricting retail store size, especially given the success of efficient supermarkets. ${ }^{11}$ It is certain, however, that if US marketers want to penetrate the French market they need to know this information to avoid business loss.

The above does not mean that all current international CI practices are not on the right track. In fact, many intensive exporters, as Calof ${ }^{12}$ and other scholars found, have been proficient in obtaining information from abroad. These exporters are more likely to utilise any source of information than less intensive exporters; they try to understand the host country more in depth and successfully implement international marketing strategies. For instance, to be successful in the Persian Gulf most American franchisers have to have some adaptability and flexibility in their operations and policy because of cultural sensitivity. ${ }^{13}$

In international IC practice, the more intensive exporters can also use personal contacts abroad for the most important sources of information. For example, one of the authors once worked as an international business consultant for a Canadian firm. He used his personal connections/relations to research useful information to help the Canadian firm successfully develop a China project. This type of information resource was named the social capital pool and its values are flexible depending on how individual organisations wish to implement it in its business practice.

\section{ON-LINE INFORMATION: OPPORTUNITIES AND CONSTRAINTS}

The advancement of technology has had some very positive effects on this industry. The communication superhighway or the Internet, apart from reshaping the business environment, is providing benefits to $\mathrm{CI}$ practitioners. The Internet not only makes it easier to obtain good quality secondary and primary information as well as providing value to existing products or services; it also helps develop competitive or business intelligence. ${ }^{14}$ Another use of the Internet is what is termed 'collaborative intelligence'. This refers to the process whereby CI professionals team up with colleagues in other divisions to leverage the firm's intellectual capital - helping design and publish 'knowledge bases'. At the same time, it is a way of identifying and developing ways to overcome hurdles to information sharing and collaboration. Educating senior executives about the Internet, and authoring 'learning modules' to help other employees learn information-seeking skills is another function of a collaborative intelligence programme. ${ }^{15}$

The Internet allows analysts to monitor competitors' activities by using on-line newsgroup postings or on-line discussion groups. Government agencies such as embassies also provide free on-line information. Obviously, the international CI practitioner should begin by obtaining free resources; this can be achieved by visiting competitors' websites, their suppliers and the specific industry in the new country. If time or 
the likelihood of obtaining the data is limited, there are now on-line business directories where this information can be purchased.

The problem with the Internet is the difficulty of determining the quality of the source. A criticism of the Internet is that standards for citing and classifying publications by subject, date, and origin are neither well established nor enforced. Another problem the authors are concerned with in their practice is that although over 90 per cent of the information on the Internet is in English, other languages are becoming more and more widely used. In practice, it is unlikely that CI professionals alone could locate useful information for CI purposes, collaboration between CI professionals and translators is necessary. This raises the costs of conducting CI through the Internet. On the other hand, due to technological problems, many languages are not yet supported on the Internet; this limitation makes it difficult to dig out more specific information pertaining to foreign competitors.

Accordingly, we also need to conduct international CI through other information channels. In fact, our experiences indicate that public and/or university libraries contain extensive amounts of information. Books provide insights into the psyche of corporations as well as the thought processes of key decision-makers. In addition, magazines and periodicals can provide details on competitors' actions. Trade journals and local and international newspapers also provide relevant and detailed information. Nor should personal contacts as sources of international information be forgotten. Relevant facts can also be gathered from the organisation's own sales force, customers, trade shows and distributors.

Once the CI unit has collected, evaluated and analysed the raw data it needs to disseminate the information to the decision-maker. In most cases, however, a comprehensive study also requires primary information, which may include surveys, interviews, observations and word of mouth. In practice, after obtaining data from inexpensive secondary sources, the firm is in a better position to conduct field studies in order to acquire true details. After obtaining secondary information and detailed primary data, a firm has a holistic perspective, which can provide an advantageous lead. We suggest that CI practitioners establish strategic alliances across national and cultural boundaries, so that the necessary back up information and in-depth analyses can be obtained when needed.

\section{THE PROCESSES OF DEVELOPING A GLOBAL CI PROGRAMME}

To win the competition in today's globalised economies it is necessary for firms involved in international business to design and develop a global CI programme. Such a programme should reflect the needs of the firms, facilitate information processes and assist strategic decision making by management. The structure and the scope of global CI programmes are various and totally depend on the individual firms. Based on previous research ${ }^{16}$ and our own experiences we suggest that in establishing a formal international CI programme, a firm needs to follow an eight-step process. These eight steps are:

- define needs

- appoint a dedicated project leader

- identify the main international competitors

- assess available resources

- set CI programme objectives and budget

- design the programme structure 
— data processing

- presentation.

\section{Step one: Defining requirements}

The CI practitioner must perform a needs assessment to determine what type of information the company requires. Knowing what information is required is key, it can make the research flow faster and more easily. A clear definition of the project needs to be made in writing with input from all function areas or departments as an effective CI programme potentially requires all staff to gather information. Asking the right questions and examining the business strategy may lead to areas that need to be addressed. At this stage, the coordinator has to be aware of cultural, social and economic differences between the home country and the potential host country.

The seven basic questions posed earlier provide a good guideline for the issues that need to be addressed, and thus suggest research/analysis areas. It is suggested that regulatory and legislative differences between the target country and the home culture, as well as all related changes that affect the competitive market are critical components for inclusion while assessing new markets and competitors' strengths and weaknesses. Contextual content, time prioritisation and sensitivity, as well as multitasking skills will deepen the analytical content and the effectiveness of the intelligence delivered. ${ }^{17}$

\section{Step two: Assign a leader}

Although most staff should be encouraged to acquire competitive information, the programme should be coordinated by one individual; this person should be open to cultural differences and be able to develop an action-oriented programme. It is suggested that this leader should have solid knowledge and be aware of global issues and diversity, active reading and listening skills, flexibility in scheduling time, and a patient, open and curious disposition towards people and cultures. ${ }^{18}$ A person familiar with different cultures, fluent in more than one language and able to listen for content without being strictly bound by context should be the right candidate.

The person heading the programme should also be able to convert mountains of information into actionable intelligence. In addition, the CI analyst needs to build an international network of professionals. In this way primary information can be readily obtained. Having analysed the information, the CI practitioner must then keep the organisation informed about the general state of their industry and competitors. Prescott and Gibbons suggest building a project-oriented approach. ${ }^{19}$ This means emphasising temporary involvement by different individuals 'funded' by different interested managers. The benefit of this type of participation is the exposure the programme has and the common perspective gained by a majority of staff. The end result is having employees acquainted with the programme and capable of being rapidly deployed to address critical business issues if required.

\section{Step three: Identify the main competitors}

It is important for firms that are involved in international businesses to conduct a competitive analysis as part of the CI programme. The purpose of competitive analysis is to better understand one's own industry and main competitors in order to develop a 
strategy that will enable the firm to gain a sustainable competitive advantage. This competitive advantage will in turn achieve continuing performance results that are superior to one's industry and competitors. For instance, a Canadian firm once hired one of the authors to conduct an international competitive intelligence. According to the client's needs, he first analysed the characteristics of that company's industry in the world, then he identified five major competitors to the company and located the positions of those five competitors in the industry worldwide. Based on the best information resources and his propounded analysis, he predicated what those five competitors were likely to do in the marketplace individually; and made some suggestions to the company as to the actions that should be taken to achieve a competitive advantage. The result turned out to be excellent.

This case, although a single one, not only demonstrates the importance of identifying one's competitors in conducting CI, it also illustrates that it is much more difficult to get information about one's international competitors. This is particularly true in industries where the market is not concentrated and competitors are widely distributed. In such a situation it is important for the CI professionals to focus on the major competitors.

\section{Step four: Assess resources}

The company needs to determine what information there is within the organisation. An assessment of knowledge, expertise, foreign national employees, and on-site materials can prove beneficial in a gap analysis. Furthermore, expatriates who have returned can provide valuable sources of competitive intelligence. At this stage it is suggested that the strategies include interviewing experts who are familiar with the subject concerned and who have lived, worked or studied in the country in question. Evaluating internal resources should be completed prior to the collection and analysis of external resources. $^{20}$

\section{Step five: Setting Cl programme objectives and budget}

The objectives of a CI programme should be seriously considered and decided, the earlier the better. The objectives, based on our own experiences, are influenced by various factors, such as the company's marketing strategy and available resources. At the same time, the objectives of a CI programme can influence every other step of the CI process. We suggest that two dimensions need to be addressed when defining the objectives, one dimension is to separate direct objectives from indirect objectives; another is to distinguish the comprehensiveness of the assignments and the type of assignments for the CI programme.

Once the objectives are defined the project coordinator has to consider the budget his/her group will need. Decisions pertaining to country visits need to made early due to scheduling, visas and inoculations that may be required. According to Robertson, the budget can sometimes dictate the number of trips that need to be made abroad. ${ }^{21}$

In addition to general administration expenses, the following need to be considered:

- the acquisition of new physical sources (books, maps, periodicals)

- additional part-time or full-time staff for collection and analysis of 
information translation and other aspects of the collection process

- training on cultural, trade or international business issues

- specialised conferences and/or association memberships

- on-site visits for collection of information.

\section{Step six: International $\mathbf{C l}$ structures}

At this stage, there needs to be an analysis of staff requirements for projects. If there are limited human resources then the CI analyst may need to cover the entire world. Robertson suggests that if the CI team is able to hire staff specifically for an internationally focused intelligence assignment, background and living experience in that culture may be preferable, but education and international orientation are the primary objectives. ${ }^{22}$

Relying on individuals who have first-hand knowledge of the country will prove to be most beneficial. According to Werther these individuals will be able to understand and deal with issues of comparative politics and development. ${ }^{23}$ They need to understand and deal with:

- processes of rapid societal change

- clashing cultural norms

- historical animosities and friendships among groups and nations, and their various impacts on regional market performance

— economic trends

- national stability

- and, ultimately, questions of corporate strategy.

At the same time it is important to develop a common language for CI, an ethical framework for the collection of information including a code of conduct, skill-building workshops related to CI topics, and a vision of how CI fits with the mission of the firm. ${ }^{24}$ The code of ethics and conduct must be flexible and suitable for use in different cultures and countries or it will be irrelevant.

Moreover, the CI programme needs to be able to counteract current threats and facilitate or establish a learning organisation. By so doing it will enable the firm to continue surviving even if competitive conditions change.

\section{Step seven: Data gathering and processing}

Prior to leaving for the international site a few things need to be arranged.

Interviews with a variety of sources need to be set up to learn as many details of the industry in the foreign country. Also, information that can be exchanged when interviewing should be prepared, since leaders recognise the value of trading facts. The CI analyst also needs to define the specific requirements and goals the visit should fulfil. For example, visiting proposed plant locations may be expected, but examining the distribution channels would also be an important part of the visit. ${ }^{25}$

Everything should be recorded with the intention of using it to complete the competitor intelligence puzzle. While at the site the CI practitioner needs to keep in mind the cultural challenges. The person should have an intimate knowledge of the effects of social, cultural and political factors on market performance along with more traditional reliance on financial, business and economic factors to gather relevant and worthy material. Failure to understand the social and political dynamics can lead to a waste of time, resources and money. ${ }^{26}$

\section{Step eight: Presentations}

Having acquired, interpreted, analysed and transformed the information, the 
last remaining step is to distribute or disseminate the intelligence. The CI programme needs to be designed to deliver proficient and complete solid analysis to people who can act on it. It has to assist in making timely, effective and competitive decisions. There might be different formats in terms of presentations but the fundamental content should be basically the same. It is up to individual CI professionals according to the management preferences to decide what types of format are the best to present the findings and recommendations. One important point for all CI professionals to keep in mind is that the final presentations should be available and accessible only to those who need the information, failure to do this may lead to great loss in terms of intellectual property.

\section{CONCLUSION}

The highly competitive global village demands that firms implement global competitive intelligence programmes to meet present and future challenges. It is undeniable that global CI is instrumental in enabling firms to successfully launch products, compete effectively or enter a new market in a timely and specific manner; it assists in facilitating effective decisions. For the CI professional, a good sense of history, politics, cultural and business knowledge is a primary requirement in building a global CI programme. These are the tools a CI analyst must possess in order to understand cultural realities and trends. Although, it is impossible to be able to understand every culture there can be an evolution towards a global mind.

It is very important for CI practitioners to know that conducting a global CI programme differs from that of a domestic one. This is where intellectually and socially curious people can acclimatise to the orientations of those worlds in which they are functioning without trying to assimilate the culture of their hosts. By doing so the CI practitioner can fully understand the effect that religion, ethnic backgrounds, and histories bring to a particular culture. With this knowledge, the analyst is then able to piece together the puzzle of global CI.

In today's highly competitive global village, knowledge and information has to be analysed and converted to intelligence to be effective and worthwhile. It is important for any company to know its competitors in terms of their products, their distribution channels and their marketing strategies. It is crucial in those cases where two companies produce similar goods and compete directly for the same market. Only in this way can the firm be assured of success in the global market.

If competitive intelligence as a dynamic business function has only recently been established, then the global CI programme is just in its introduction stage. At this time both academic scholars and business practitioners are short of theories and practices to research, much more work needs to be done for the practice of global competitive intelligence to mature. The authors' experiences and practice demonstrate that CI alone will not guarantee success in today's environment but, if CI, in some form, is not a part of the decision-making process, sooner or later a company will lose a crucial marketplace battle to a competitor. We hope our research will be useful to all those who are interested in either research about or practice in the fields of global competitive intelligence. 


\section{Acknowledgment}

The authors acknowledge that the paper was partially presented to 2000 NEBAA International Conference, Southern Connecticut University, New Haven, Connecticut, 28-29th April, 2000.

\section{References}

1 Simpkins, R. (1998) 'The global mind', Competitive Intelligence Magazine, Vol. 1, No. 2, July-September.

2 Terpstra, V. and Sarathy, R. (1997) 'International marketing', (Seventh edition), The Dryden Press, Forth Worth, TX.

3 Vedder, R. and Vanecek, M. (1998) 'Competitive intelligence for IT resource planning', Information Strategy, Vol. 15, No. 1, Fall.

4 Tian, R. G. (2000) 'The implications of rights to culture in trans-national marketing: An anthropological perspective', paper presented to the Society for Applied Anthropology 2000 Annual Meeting, San Francisco, 21st-26th March, 2000

5 Feiler, G. (1999) 'Middle East CI sources: Problems and Solutions', Competitive Intelligence Review, Vol. 10, No. 2

6 Prescott, J. and Gibbons, P. T. (1993) 'Global competitive intelligence: An overview', Society of Competitive Intelligence Professionals, Alexandria, VA.

7 Simpkins (1988) op. cit.

8 Sheinin, C. (1996) 'Assessing global competition',
Competitive Intelligence Review, Vol. 7, No. 3.

9 Calof, J. (1997) 'So you want to go international? What information do you need and where will you get it?', Competitive Intelligence Review, Vol. 8, No. 4.

10 Tian (2000) op. cit.

11 Griffith, D. (1998) 'Cultural meaning of retail institutions: A tradition-based culture examination', Journal of Global Marketing, Vol. 12, No. 1, pp. 47-59.

12 Calof (1997) op. cit

13 Martin, J. (1999) 'Franchising in the Middle East', Management Review, June, pp. 38-42.

14 Graef, J. (1997) 'Using the Internet for competitive intelligence: A survey report', Competitive Intelligence Review, Vol. 8, No. 4.

15 Calof (1997) op. cit.

16 Robertson, M. (1998) 'Seven steps to global CI', Competitive Intelligence Review, Vol. 1, No. 2.

17 ibid.

18 ibid.

19 Prescott and Gibbons (1993) op. cit.

20 Robertson (1998) op. cit.

21 ibid.

22 ibid.

23 Werther, G. (1998) 'Doing business in the new world disorder: The problem with "Precision", Competitive Intelligence Magazine, Vol. 1, No. 2, July-September.

24 Prescott and Gibbons (1993) op. cit.

25 Robertson (1998) op. cit.

26 Werther (1997) op. cit. 